\title{
Post-secondary Science Students' Understanding on Mole Concept and Solution Concentration
}

\author{
Sheau Huey Chong ${ }^{1, *}$, Norlia Goolamally ${ }^{2}$, Kwan Eu Leong ${ }^{3}$ \\ ${ }^{1}$ Open University Malaysia, Tunku Abdul Rahman University College, Malaysia \\ ${ }^{2}$ Open University Malaysia, Malaysia \\ ${ }^{3}$ University Malaya, Malaysia
}

Copyright $(2019$ by authors, all rights reserved. Authors agree that this article remains permanently open access under the terms of the Creative Commons Attribution License 4.0 International License

\begin{abstract}
Due to their abstract nature, the mole concept and solution concentration are difficult for students to understand and apply to stoichiometric calculations. This study was designed to investigate students' perceptions and difficulties in solving problems related to the mole concept and solution concentration. Thirty-eight students (18-19 years old) who were pursuing science related programmes from a private university college in Malaysia participated in the study. Students were asked to answer twenty-five open-ended questions on the mole concept and solution concentration. Analysis of students' responses revealed that they were not able to connect the mole concept with mass and number of particles. Students were also grappling to answer problems regarding concentration and dilution. This study suggests that it is important to determine whether students' difficulties to master the concepts are due to lack of knowledge or the presence of alternative frameworks so that so that pedagogical instruction can be modified. This study was part of a larger research project where students' responses on this open-ended test will be used to get a greater generalizability in order to construct the alternatives to the four-tier multiple choice (4TMC) instrument to identify students' alternative frameworks on these concepts.
\end{abstract}

Keywords Four-tier Multiple Choice Instrument, Alternative Frameworks, Stoichiometry, Macroscopic, Sub-microscopic

\section{Introduction}

Chemistry is perceived as an abstract subject by students with limited connection to day-to-day living [1, 2]. The complexity of the calculations involved, teacher-centred based instruction using an explain-apply pedagogy [3] and over emphasis in examinations may cause learners to fail to appreciate the contribution of chemistry to the development of society [1].

Dori and Hameiri [4] stated that understanding chemistry is a complex human activity and learners must navigate concepts among three levels of representation termed by Johnstone [5] as macroscopic, sub-microscopic and symbolic modes of representation. While experts are able to process these three levels of representation with ease, Johnstone [6] claimed that this presented too much complexity for the beginner as it involves 'multilevel thought' where students are expected to negotiate the three levels of chemical knowledge concurrently. Learners' inability to move within the three modes of representation always leads to rote learning and development of alternative frameworks about many chemistry concepts [7-9]. Chandrasegaran, Treagust, and Mocerino [10] claimed that successful learning outcomes in chemistry are dependent on one's capability to conceptualize sub-micro particles comprising indescribably small molecular entities to explain tangible chemical phenomena at the macro level. The usual assessment methods are not able to provide adequately detailed information regarding students' conceptual understanding as these assessments normally examine learners' ability to state definitions, reproduce proofs, and solve standard numerical problems [11].

The mole concept is widely applied in chemistry. One of the most important applications is in stoichiometry. Stoichiometry deals with the quantitative relationship between reactants and products in chemical reactions. In addition, solution concentrations are also rooted in the mole concept. Hence, understanding the mole concept underpins a significant part of a students' learning in chemistry. According to Gilchrist [12], mole concept is the most far-reaching chemistry concept in its application and reasoning with this concept is the gateway to the world of quantitative chemistry $[13,14]$. Furio, Azcona, and Guisasola [15] stressed that mole concept serves as a 'conceptual bridge', which connects the macroscopic (mass) and the sub-microscopic (number of particles) worlds. The macroscopic aspect is useful in the laboratory 
when one is doing experiments; whereas the sub-microscopic component plays an important role to explain the nature of chemical reactions.

There has been a growing interest and frequent discussion among chemistry education researchers over recent decades with the teaching and learning of mole concept [16-19]. The very fact that so much discussion has been devoted to this concept is evidence of such essential importance of understanding the mole concept. Such studies have provided a wealth of knowledge on learning difficulties faced by students on the topic. Mole concept, as a fundamental topic in chemistry, is featured prominently in high school chemistry [20] and is also taught in chemistry courses at the pre-university and tertiary levels [3] and this is the case in the local Malaysian context as well. Studies abroad have often showed that many students have a weak understanding of the mole concept even after formal education [21, 22]. A prominent educational problem inherent to this concept is the tendency of students to approach mole problem solving in an algorithmic manner without conceptual understanding and this has been indicated by past studies in which students demonstrated greater success in solving algorithmic-based mole concept problems as compared to questions which require higher-order thinking skills and conceptual understanding [23].

Lythcott [24] claimed that in chemistry education setting, success at many levels of chemistry assessment does not provide a good indication of conceptual understanding among students. Studies on students' understanding of chemistry maintain that students mostly take the algorithmic strategy in solving chemistry problems without giving much attention to conceptual understanding [23]. Nicoll claimed that current instructional practices for chemistry do not facilitate conceptual understanding [25]. Added to that, the concept of solution concentration is foundational to solution chemistry [26]. Lack of conceptual understanding in the mole concept and solution concentration will hinder students' progress especially when they have to undertake final-year hands-on project and industrial training. As students will spend a large amount of time in laboratories for these two activities, the success of it very much rely on their ability to apply the mole concept and solution concentrations knowledge they have acquired in formal chemistry lessons.

Within the local educational scene, formal chemistry lessons are first taught to Form Four (16-17 years old) science stream students. Mole concept is covered under topic chemical formulae and equations. After the lesson, a student is expected to be able to define the meaning of mole, state the meaning of Avogadro's constant; relate the number of particles in one mole of a substance with the Avogadro's constant; solve numerical problems to convert the number of moles to the number of particles of a given substance and vice versa [27]. On the other hand, solution concentration is not only incorporated in Topic acids and bases, but also to Form Four science stream students. The learning outcomes for this concept are as follows: to state the meaning of concentration, molarity, the relationship between the number of moles with molarity and volume of a solution; describe methods for preparing standard solutions; describe the preparation of a solution with a specified concentration using dilution method; relate $\mathrm{pH}$ value with molarity of acid and alkali and solve numerical problems involving molarity of acids and alkalis [27]. When students enroll to chemistry related programs at tertiary level, they will encounter the two concepts again with more in-depth coverage.

Past studies have shown students' difficulties in solving mole concepts and solution concentration problems across all levels of education. For example, students always identify the 'amount of substance' with mass and occasionally, with volume; treating the meaning of mole and molarity as the same, facing difficulty in solving stoichiometric proportion in a reaction which is not $1: 1$ and not able to differentiate between the number of mole of a molecule and its respective ions [28-32]. Students' inability to master these two concepts are either due to lack of knowledge or they hold alternative frameworks for these concepts. While various studies have been carried out regarding students' conception, understanding and difficulties in the mole concept and solution concentration, most of the studies target group was secondary school students. Alternative frameworks uncovered for post-secondary level students in any study are relatively few. It is likely that these studies did not cover sufficient breadth and depth. Also, most of the studies are, strictly speaking, an assessment test rather than a diagnostic test. Without thorough understanding of the mole concept, students will only gain superficial understanding of solution concentration and their knowledge in these two concepts will be always fragmented. Alternative frameworks held by students in these two concepts will pose as a barrier as they embark to higher level of science learning generally and chemistry specifically if they are not rectified. It is important for both students and educators to ascertain the real cause of students' difficulties in understanding these topics. If the cause is due to lack of knowledge, more time should be allocated in learning and teaching instruction; if students hold a specific alternative framework for the topics, a different instructional approach needs to be employed to address the problem about which many students are relatively confident. In investigating students' alternative frameworks, multiple-choice questions (MCQs) are frequently used. Typical MCQs require students to choose the correct answer to a given question from a given set of options. According to Reynolds, Livingston and Wilson [33], MCQs are versatile, unbiased, easy to use, efficient and less influenced by an individual's tendency to answer in a particular way. However, typical MCQs are not able to differentiate correct answers due to correct reasoning from those, which 
are due to incorrect reasoning [34]. Two-tier multiple choice (2TMC) questions are subsequently developed to address the weakness and have since become one of the most popular members of the family of MCQs in uncovering students' alternative frameworks $[35,36]$. 2TMC tests are better than typical MCQs to probe students' alternative frameworks as they measure student's ability to select correct answers as well as reasoning behind their choices. Nevertheless, 2TMC tests are not able to distinguish mistakes resulting from lack of knowledge or from mistakes due to genuine alternative frameworks [34]. This limitation can be addressed significantly by incorporating confidence ratings as additional tiers to 2TMC tiers [33]. A four-tier multiple choice (4TMC) test item involves the answer and reasoning tiers of $2 \mathrm{TMC}$ tests, with additional tiers requiring students to specify confidence rating separately for their choice of responses in the answer and reasoning tiers [34, 37-38]. The objective of this study was to investigate post-secondary science students' perceptions and difficulties in solving problems on the mole concept and solution concentration through the open-ended test in order to get a greater generalisability to construct the distractors of the 4TMC diagnostic instrument.

\section{Methodology}

\subsection{Selection of Participants}

Thirty-eight first year students (18-19 years old) pursuing science related programmes where chemistry is a core subject from a private university college in Malaysia participated in the study. This group of students was the only cohort available at the time of this study. Students had completed six years of primary and five years of secondary education in Malaysia prior to this research. Students had spent the last two years of their secondary schooling studying chemistry. They were first taught the mole concept and solution concentration in the first year (Form 4) of secondary school chemistry curriculum. The participants in this study come from different states in Malaysia with diverse background.

\subsection{Instrumentation}

This study was part of a larger research project in which the authors planned to develop a 4TMC instrument to identify post-secondary level science students' alternative frameworks on the mole concept and solution concentration. Galloway [39] stated that diagnostic testing is one of the most powerful components in the toolbox of evidence-based education as it provides quantitative perspective of student understanding. Diagnostic test is a distinct form of measurement, as its purpose is to ascertain, prior to instruction, each student's strengths, weaknesses, knowledge, and skills. The main aim of administering the open-ended test was to get a greater generalizability in order to construct the distractors of the 4TMC test on the mole concept and solution concentration. Added to that, open-ended test can be administered efficiently as they allow participants to complete the test items without any intervention or direct guidance from the researchers. Hence, the chances of misinterpretation will be smaller compared to interview. These questions were chosen or modified from previous past year questions from Cambridge A Levels, National Chemistry Quiz organized by Malaysian Institute of Chemistry (IKM), past semester examination papers from the university where participants of this research is studying and established university textbooks to test students' thinking skills, conceptual understanding and application to real life situations.

Students from the science related programmes have learned the mole concept and solution concentration prior to the study. In this study, students were asked to answer twenty-five open-ended questions on the mole concept and solution concentration. Students were given two hours to answer the questions. All questions and answers to the open-ended diagnostic test on the mole concept and solution concentration were content validated by two senior lecturers in chemistry from a local university. The processes of constructing the open-ended diagnostic test were as follows:

(i) The first stage involved the identification and careful study of the content and learning objectives of the mole concept and solution concentration as specified in the Malaysia curriculum for secondary and pre-university levels.

(ii) The construction of the open-ended questions and answers began and discussion was carried out with the experts.

(iii) The open-ended questions and answers were content validated by the chemistry lecturers.

(iv) Revision and modification of the questions and answers were carried out.

(v) The final version of the test (after revision and modification) was approved by the chemistry lecturers before being administered to students.

\subsection{Data Collection Procedures}

A meeting was held among the researchers and the senior chemistry lecturers in May 2017. The researcher explained the aim and working plans of this study to them. The first draft of the open-ended diagnostic test on the mole concept and solution concentration was presented to the lecturers for comments and modification in order to establish content validity. The revised version of the open-ended diagnostic test on the mole concept and solution concentration diagnostic test was administered to the thirty-eight students in July 2017. Approval from the university's research ethics committee was obtained for the 
conduct of this study. Students were briefed on the background information of the study. They were informed that the participation was on a voluntary basis and they can withdraw from the study at any time without any consequences. All students who agreed to participate in the study were required to sign a consent form prepared by the university's research ethics committee. The test was supervised by chemistry lecturers teaching the participants in this study. The lecturers were briefed by the researcher of this study prior to the test. Most of the students managed to complete the test within two hours.

Categorization and analysis of the results was carried out by the researchers. Similar responses given to each item formed a category. Each category of an item included the correct conception and wrong reasoning/steps, but sometimes some deficient or meaningless responses emerged. The most prevalent categories emerged was selected to guide the design of the distractors on the 4TMC instrument, in addition to the related literature review.

\section{Results}

\subsection{Categorization of Students' Answers on the Open-Ended Test on Mole Concept and Solution Concentration}

Students' answers to the items on the open-ended test were carefully investigated and each student's answer was assigned to an appropriate category. In determining the categories, the meaningful responses given by the students to an item were identified, and the frequency of answers for each category was counted by analyzing students' responses. Table 1 shows the categories that emerged from the students' responses and their frequency for each item on the open-ended test.

\subsection{Analysis of Reasoning Categories in the Open-Ended Test Results}

The analysis of the reasoning categories emerged from the open-ended test results is presented in relation to the reports on students' difficulties in solving the mole concept and solution concentration in the literature. Students' difficulties similar to the ones in the literature and the ones were not mentioned in previous literature were identified in order to construct the distractors on the 4TMC test on the mole concept and solution concentration.

The first item of the open-ended test asked student to state whether the statement was true or false. The statement was regarding the relationship between mole concept and number of particles. Although most students gave a correct answer but only twelve out of thirty-eight students gave a correct answer with explanation. Twenty-four students only stated that the statement was correct without further explanation.

The second item on the open-ended test was presented in sub-microscopic form where it required students to show the results pictorially. Only twelve students were able to show the correct answer. Fourteen students who provided wrong answer showed that they were either not aware or they assumed nitrogen and hydrogen exist as atoms. The low success rate of the question was similar to the studies carried out by [26]. The studies reported that tertiary students were much more successful in solving the questions that were presented in macroscopic form than sub-microscopic form.

Table 1. Categories of the students' responses for each item on the open-ended test

\begin{tabular}{|c|c|c|c|}
\hline Item No & Category Label & Category Description & Frequency \\
\hline \multirow{3}{*}{1} & A & Correct answer (with explanation) & 12 \\
\hline & $\mathrm{B}$ & Correct answer (without explanation) & 24 \\
\hline & $\mathrm{C}$ & Wrong answer & 2 \\
\hline \multirow{4}{*}{2} & A & Correct answer & 12 \\
\hline & $\mathrm{B}$ & Confused between atom and molecule & 14 \\
\hline & $\mathrm{C}$ & Responses were not meaningful. & 6 \\
\hline & $\mathrm{D}$ & Question was not answered & 6 \\
\hline \multirow{4}{*}{3} & A & Correct answer & 19 \\
\hline & $\mathrm{B}$ & Did not consider limiting and excess reactants & 5 \\
\hline & $\mathrm{C}$ & Responses were not meaningful & 2 \\
\hline & $\mathrm{D}$ & Question was not answered & 12 \\
\hline \multirow{3}{*}{4} & A & Correct answer & 31 \\
\hline & $\mathrm{B}$ & Lack of understanding between mole and particles & 5 \\
\hline & $\mathrm{C}$ & Question was not answered & 2 \\
\hline
\end{tabular}




\begin{tabular}{|c|c|c|c|}
\hline Item No & Category Label & Category Description & Frequency \\
\hline \multirow{4}{*}{5} & A & Correct answer & 32 \\
\hline & $\mathrm{B}$ & Wrong conversion of unit & 1 \\
\hline & $\mathrm{C}$ & Responses were not meaningful & 4 \\
\hline & $\mathrm{D}$ & Question was not answered & 1 \\
\hline \multirow{3}{*}{6} & A & Correct answer & 31 \\
\hline & $\mathrm{B}$ & Assumed number of water molecules is one & 5 \\
\hline & $\mathrm{C}$ & Calculation error (might be due to carelessness) & 2 \\
\hline \multirow{4}{*}{7} & A & Correct answer & 29 \\
\hline & $\mathrm{B}$ & Lack of understanding in mole concept & 7 \\
\hline & $\mathrm{C}$ & Wrong formula used & 1 \\
\hline & $\mathrm{D}$ & Responses were not meaningful & 1 \\
\hline \multirow{4}{*}{8} & A & Correct answer & 14 \\
\hline & $\mathrm{B}$ & Lack of understanding in mole concept & 12 \\
\hline & $\mathrm{C}$ & Responses were not meaningful & 7 \\
\hline & $\mathrm{D}$ & Question was not answered & 5 \\
\hline \multirow{5}{*}{9} & A & Correct answer & 17 \\
\hline & $\mathrm{B}$ & Not able to relate mole and volume of gas & 9 \\
\hline & $\mathrm{C}$ & Did not consider limiting and excess reactants & 1 \\
\hline & $\mathrm{D}$ & Responses were not meaningful & 9 \\
\hline & $\mathrm{E}$ & Question was not answered & 2 \\
\hline \multirow{4}{*}{10} & A & Correct answer & 21 \\
\hline & $\mathrm{B}$ & Lack of understanding in atoms, molecules and mole concept & 10 \\
\hline & $\mathrm{C}$ & Responses were not meaningful & 3 \\
\hline & $\mathrm{D}$ & Question was not answered & 4 \\
\hline \multirow{5}{*}{11} & A & Correct answer (with working steps) & 19 \\
\hline & $\mathrm{B}$ & Correct answer (without working steps) & 1 \\
\hline & $\mathrm{C}$ & Assumed chlorine exist as atoms & 3 \\
\hline & $\mathrm{D}$ & Lack of understanding between ratio and the composition of a substance & 12 \\
\hline & $\mathrm{E}$ & Responses were not meaningful & 3 \\
\hline \multirow{3}{*}{12} & A & Correct answer & 25 \\
\hline & $\mathrm{B}$ & Lack of understanding in mass and mole concept & 6 \\
\hline & $\mathrm{C}$ & Question was not answered & 7 \\
\hline \multirow{4}{*}{13} & A & Correct answer & 16 \\
\hline & $\mathrm{B}$ & Lack of understanding between mole of molecules and mole of ions & 13 \\
\hline & $\mathrm{C}$ & Responses were not meaningful & 1 \\
\hline & $\mathrm{D}$ & Question was not answered & 8 \\
\hline \multirow{4}{*}{14} & A & Correct answer & 18 \\
\hline & $\mathrm{B}$ & Lack of understanding in concentration, mass and mole & 7 \\
\hline & $\mathrm{C}$ & Wrong units conversion & 2 \\
\hline & $\mathrm{D}$ & Question was not answered & 11 \\
\hline \multirow{4}{*}{15} & A & Correct answer & 30 \\
\hline & $\mathrm{B}$ & Lack of understanding between ratio and mole concept & 2 \\
\hline & $\mathrm{C}$ & Responses were not meaningful & 2 \\
\hline & $\mathrm{D}$ & Question was not answered & 4 \\
\hline
\end{tabular}




\begin{tabular}{|c|c|c|c|}
\hline Item No & Category Label & Category Description & Frequency \\
\hline \multirow{5}{*}{16} & A & Correct answer & 27 \\
\hline & $\mathrm{B}$ & Lack of understanding between ratio, mass and mole concept & 3 \\
\hline & $\mathrm{C}$ & Assume 1:1 proportion between two substances & 1 \\
\hline & $\mathrm{D}$ & Responses were not meaningful & 2 \\
\hline & E & Question was not answered & 5 \\
\hline \multirow{5}{*}{17} & A & Correct answer & 4 \\
\hline & $\mathrm{B}$ & Did not answer the whole part of the question ( 2 out of 3 parts are correct) & 6 \\
\hline & $\mathrm{C}$ & Lack of understanding between concentration nad mole concept & 9 \\
\hline & $\mathrm{D}$ & Responses were not meaningful & 2 \\
\hline & E & Question was not answered & 17 \\
\hline \multirow{4}{*}{18} & A & Correct answer & 5 \\
\hline & B & Not able to convert concentration in parts per million (ppm) to molarity & 13 \\
\hline & $\mathrm{C}$ & Responses were not meaningful & 2 \\
\hline & $\mathrm{D}$ & Question was not answered & 18 \\
\hline \multirow{6}{*}{19} & A & Correct answer & 18 \\
\hline & B & Assume 1:1 proportion between two substances & 6 \\
\hline & $\mathrm{C}$ & Lack of understanding between the mole concept and volume of the solution & 2 \\
\hline & $\mathrm{D}$ & Lack of knowledge on burrette reading & 2 \\
\hline & $\mathrm{E}$ & Responses were not meaningful & 2 \\
\hline & $\mathrm{F}$ & Question was not answered & 8 \\
\hline \multirow{5}{*}{20} & A & Correct answer & 10 \\
\hline & $\mathrm{B}$ & Lack of understanding regarding percentage by weight of an acid & 4 \\
\hline & $\mathrm{C}$ & Lack of understanding on dilution concept & 2 \\
\hline & $\mathrm{D}$ & Responses were not meaningful & 4 \\
\hline & E & Question was not answered & 18 \\
\hline \multirow{4}{*}{21} & A & Correct Answer & 8 \\
\hline & $\mathrm{B}$ & Assume 1:1 proportion between two substances & 12 \\
\hline & $\mathrm{C}$ & Lack of understanding on dilution concept & 7 \\
\hline & $\mathrm{D}$ & Question was not answered & 11 \\
\hline \multirow{3}{*}{$22 \mathrm{a}$} & A & Correct answer & 24 \\
\hline & B & Answer with wrong unit & 1 \\
\hline & $\mathrm{C}$ & Question was not answered & 13 \\
\hline \multirow{4}{*}{$22 b$} & A & Correct answer & 19 \\
\hline & $\mathrm{B}$ & Careless mistake (correct steps with wrong answer) & 3 \\
\hline & $\mathrm{C}$ & Responses were not meaningful & 2 \\
\hline & $\mathrm{D}$ & Question was not answered & 14 \\
\hline \multirow{4}{*}{$22 \mathrm{c}$} & A & Correct answer & 1 \\
\hline & $\mathrm{B}$ & Lack of understanding in mole concept and concentration & 14 \\
\hline & $\mathrm{C}$ & Responses were not meaningful & 1 \\
\hline & $\mathrm{D}$ & Question was not answered & 22 \\
\hline \multirow{4}{*}{23} & A & Correct answer & 3 \\
\hline & $\mathrm{B}$ & Lack of understanding in mole concept, concentration and dilution & 9 \\
\hline & $\mathrm{C}$ & Responses were not meaningful & 2 \\
\hline & $\mathrm{D}$ & Question was not answered & 24 \\
\hline
\end{tabular}




\begin{tabular}{|c|c|c|c|}
\hline Item No & Category Label & Category Description & Frequency \\
\hline \multirow{4}{*}{24} & A & Correct answer & 19 \\
\hline & $\mathrm{B}$ & Lack of understanding in mole concept, concentration and dilution & 2 \\
\hline & $\mathrm{C}$ & Responses were not meaningful & 2 \\
\hline & $\mathrm{D}$ & Question was not answered & 15 \\
\hline \multirow{4}{*}{$25 \mathrm{a}$} & A & Correct answer (with explanation) & 14 \\
\hline & B & Correct answer (without explanation) & 8 \\
\hline & $\mathrm{C}$ & Lack of understanding in mole concept, concentration and dilution & 9 \\
\hline & $\mathrm{D}$ & Question was not answered & 7 \\
\hline \multirow{5}{*}{$25 \mathrm{~b}$} & A & Correct answer (with explanation) & 12 \\
\hline & $\mathrm{B}$ & Correct answer (vague explanation) & 3 \\
\hline & $\mathrm{C}$ & Correct answer (without explanation) & 8 \\
\hline & $\mathrm{D}$ & Lack of understanding in mole concept, concentration and dilution & 4 \\
\hline & $\mathrm{E}$ & Question was not answered & 11 \\
\hline
\end{tabular}

In the context of the third item, the questions were presented in both the macroscopic and sub-microscopic forms. Students were required to determine the limiting and excess reactants in order to answer the questions correctly. Analysis of students' responses showed that nineteen out of thirty-eight students were able to answer the questions successfully. One of the categories that emerged revealed that students did not consider the factor of limiting and excess reactants when answering the question. Twelve students did not provide any answer for this item. Time constraint was not an issue as students were given two hours to complete the test. The low success rate in answering this question might be due to the concern raised by Johnstone [6] that the requirement to master the three levels (macroscopic, sub-microscopic and symbolic) of chemical knowledge simultaneously caused too much complexity for novice learners.

Item four tested students' understanding regarding the relationship between mass, mole concept and number of particles. Analysis of the responses to the item indicated that majority of the students (thirty-one out of thirty-eight students) managed to give a correct answer; with correct reasoning and calculation steps.

The result from the fifth item also showed that most students (thirty-two out of thirty-eight) did not face difficulties answering the question, which focused on relationship between the volume of the gas and the mole concept.

For the sixth item, five out of thirty-eight students assumed that the number of water molecule present was one instead of five when they were asked to determine the percentage composition of a hydrated substance. It is not known why students did not consider the water molecules in their working steps. Further investigation was needed in order to understand students' perception on hydrated substance.

Item seven required students to convert between number of particles, number of mole and mass from a given balanced equation. Nine out of thirty-eight students did not answer the question correctly with some of them displayed lack of understanding of the mole concept in their working steps.

Item eight assessed students' conceptual understanding on the mole concept. Analysis of this item showed that only fourteen out of thirty-eight students were able to provide correct working steps, which reflected their understanding of the concept. Other students displayed responses, which indicated their confusion regarding this concept was either from lack of knowledge or they were holding alternative frameworks of the concepts.

Although seventeen out of thirty-eight students were able to display correct working steps for item nine, a category emerged from this item in which nine students' responses showed that they did not relate both the volume of the gases and the mole concept. It was not known that this phenomenon was due to the lack of knowledge or students held alternative frameworks on this topic.

For the tenth item, ten students who showed wrong working steps in their responses indicated that their understanding related to the number of particles and the mole concept was insufficient.

Students displayed lacked of understanding between ratio and the composition of a substance for item eleven when they were asked to deduce a balanced equation based on the mass of the reactants.

Item twelve assessed students' understanding regarding the mass of substances and the mole concept. A combined of thirteen out of thirty-eight students did not succeed in answering this question. They either demonstrated lack of understanding regarding the mass and the mole concept or did not answer the question at all.

A category that emerged from the analysis of item thirteen indicated that students only have superficial understanding regarding the difference between amount of molecules and amount of ions. Some students treated them as the same entity as shown in their working steps. 
Item fourteen required students to relate the mass, mole concept, and concentration of a solution. Out of thirty-eight students, twenty students scored wrongly in which they either showed their lack of understanding of the concepts or they did not provide any answers for the question. Added to that, two students performed wrong unit conversion.

Only eight students did not manage to answer item fifteen correctly, which assessed students' knowledge regarding the relationship between the mole concept, concentration, and the volume of gases. Out of this eight students, two students demonstrated their lack of understanding between the relationship of coefficient of the equation and the mole concept. Four students did not answer the question and two students gave responses, which were not meaningful.

Two balanced equations were given in item sixteen, which assessed students' understanding on the mole concept, concentration, and the relationship between the two equations. Eleven out of thirty-eight students failed to give correct responses for the item. Out of this eleven students, three students showed their limited knowledge on the mole concept and one student assumed 1:1 proportion between two substances in the working steps. This is consistent with the finding from a study carried out by Vincent [30] on students' volumetric concept. Another seven out of the eleven students' answer was either not meaningful or they did not attempt the question.

Seventeen out of thirty-eight students did not attempt item seventeen which tested students on their understanding regarding the difference between the concentration of molecules and ions. Upon further investigation by the researchers, it was found that the word "IONS" caused confusion to students as they were not sure which ion/ions the question was referring. Therefore, there was no any conclusion drawn from this item.

Only five out of thirty-eight students scored in item eighteen. Majority of students showed lacked of knowledge when concentration of solution is expressed in parts per million (ppm). Although parts per million (ppm) is widely used to label concentration of minerals in food and beverages, students were often not introduced to this concentration unit during lesson in classroom setting.

Analysis of the results from item nineteen showed that students again (similar to item sixteen) assumed 1:1 proportion between two substances even though a balanced equation was already included in the question. A study done by Vincent [30] showed the similar results where students assumed 1:1 proportion under any circumstances. Students also displayed lack of understanding between number of mole and volume of the solution.

Item twenty assessed students' understanding associated with percentage, density and dilution regarding an acid solution. Although question from this item was a basic knowledge in science laboratory, only ten out of thirty-eight students demonstrated correct working steps in their responses. Eighteen students did not attempt the question. This raises a prospect that students might not be able to apply what they have learned in classroom. Further investigation was needed to ascertain the real cause of the gap between classroom teaching and application in laboratory.

The categories that emerged from item twenty-one also showed that students faced problems in answering question on dilution. Their understanding on dilution was superficial. Besides that, they also assumed 1:1 proportion between substances in this question. Nevertheless, equation was not provided for this item compared to item sixteen and nineteen.

Item twenty-two was divided into three parts. Most students were able to answer part (a) correctly which tested students' knowledge on the molarity of a solution. However, thirteen students did not attempt the question. Informal interview with students found that some students felt fatigued towards the end of the test although they were given sufficient time to complete it. Added to that, some students might felt overwhelmed by the item as it contained much more information than other items. Similar to part (a), although nineteen out of thirty-eight students gave correct responses, fourteen students did not answer question in part (b) which required students to make connection between the mass, mole concept, and concentration. Only one student scored in part (c) which focused on the mole and dilution concept of an ion. Twenty-two out of thirty-eight students did not attempt answering the question.

Similar to item twenty-two, item twenty-three contained a lot of information, which might cause mental fatigue to students. Twenty-four out of thirty-eight students did not give any responses to this question. Therefore, no conclusion can be made from this item.

Nineteen out of thirty-eight students scored correctly in item twenty-four which assessed students' understanding regarding concept of dilution. Fifteen students did not attempt the question. Two students were not able to connect the mole concept, concentration, and dilution; whereas responses from another two students were not meaningful.

Item twenty-five was presented in ordinary multiple choice format in sub-microscopic form to assess students understanding on the mole concept and solution concentration. Although more than $60 \%$ of students selected correct answers for both part (a) and part (b), some of them were not able to explain the rationale of their selections. This is the limitation of ordinary multiple choice tests as they fail to offer deep enough insight into students' ideas on the topic and they may provide correct answers for wrong reasons [40], so the scores obtained by students may be overestimated [41]. Nevertheless, explanations provided by students provided useful information to the researchers as it showed that they faced 
challenges to grasp the concepts of mole and molarity despite having learnt the two concepts at secondary level.

\section{Discussion \& Conclusions}

Analysis of the open-ended test demonstrated that students' knowledge on the mole concept and solution concentration was fragmented in nature. Students are expected to relate between the number of moles with molarity and volume of a solution based on the learning outcome of the topics [27]. However, the results of this study have shown that, even though students seemed to answer easily the standard textbook questions by rote learning after formal instruction, they were still unable to connect their knowledge to different contexts, which required a deep level of comprehension. The comparatively high percentage of not-answered and not meaningful responses to the open-ended test items might be an indicator of their loosely organized and fragmented knowledge in this topics.

In terms of conceptual understanding on the mole concept and solution concentration, some concepts were considered to be more problematic and might be considered as probable alternative frameworks to be assessed in the 4TMC test. In dealing with questions presented in sub-microscopic form, about half of the students were confused between atoms and molecules. Berg [26] claimed that students were much more successful in solving the questions presented in macroscopic form than sub-microscopic form. This could be due to some macroscopic form questions only required fixed memorized algorithmic steps, which do not promote conceptual understanding.

The analysis from the open-ended test also showed that students did not fully understand the difference between the coefficient and the composition of a substance in a balanced chemical equation such as $2 \mathrm{NaOH}+\mathrm{H}_{2} \mathrm{SO}_{4} \rightarrow$ $\mathrm{Na}_{2} \mathrm{SO}_{4}+2 \mathrm{H}_{2} \mathrm{O}$. In some of the cases, responses given by students indicated that they did not know the coefficient is the ratio between the substances and the superscript is the composition of the substances.

A result similar to the study carried out by Vincent [30] was obtained in this open-ended test where students always assume 1:1 proportion under any circumstances between two substances. In addition to that, analysis of the results from this test also revealed that students' understanding on concentration and dilution was superficial. In some cases, it appeared that students did not know the difference between the meaning of mole and molarity.

Mole concept and solution concentration problems come in a variety of forms. Our findings suggested that overall, students have difficulties mastering the concepts in both macroscopic and sub-microscopic modes. They were not able to make connection of the two concepts and treat them 2as separate entity. Students often think that there is no difference between the mass and the mole of a substance. Added to that, students always assume the proportion is 1:1 for all reactions as shown in item twenty-one. Students' responses from this open-ended test provided important information to the researchers as they can be used as distractors in the construction of 4TMC test instrument. The results from this study indicate that it is crucial to ascertain whether students' difficulties to understand the two concepts are due to lack of knowledge or presence of alternative frameworks. If the cause is due to lack of knowledge, more time should be allocated to in the learning and teaching instruction. However, if students hold specific alternative frameworks for the topics, a different instructional approach needs to be employed to address the problem about which many students are relatively confident. Teaching and learning of the mole concept is an important issue because of its consequences for the solving of solution concentration problems. In addition, mole concept and solution concentration also provide a wealth of valuable information about the nature of chemistry. Thus, the findings from this open-ended test and past literatures will be used to construct the distractors of the 4TMC diagnostic instrument which could possibly surface post-secondary science students' alternative frameworks

\section{Limitations of the Study}

The relatively small sample size did not represent the whole post-secondary science student population in the country. The generalizability of the findings was restricted to the particular cohort of students took part in the study. The performance of the students in the open-ended test cannot be taken as a proxy for their overall proficiency in mole concept and solution concentration as the test can only assess on selected aspects of the topic. Also, a diagnostic test is not an achievement test. Thus, students are likely to score low in such tests 


\section{Appendix}

\section{An Open-Ended Test on the Mole Concept and Solution Concentration}

1) Is the following statement TRUE or FALSE?

$1 \mathrm{~mol}$ of carbon dioxide contains $6.02 \times 10^{23}$ molecules of carbon dioxide.

2) Nitrogen reacts with hydrogen to form ammonia. Represent each nitrogen atom by a circle and each hydrogen atom by a square. Starting with FIVE molecules of both nitrogen and hydrogen, show pictorially what you have after the reaction is completed.

3) Given the balanced chemical equation:

$2 \mathrm{C}_{2} \mathrm{H}_{5} \mathrm{SH}(\mathrm{g})+9 \mathrm{O}_{2}(\mathrm{~g}) \rightarrow 4 \mathrm{CO}_{2}(\mathrm{~g})+2 \mathrm{SO}_{2}(\mathrm{~g})+6 \mathrm{H}_{2} \mathrm{O}(\mathrm{g})$

Determine the number of molecules of $\mathrm{SO}_{2}$ that would be formed starting from the actual number of molecules of $\mathrm{C}_{2} \mathrm{H}_{5} \mathrm{SH}$ and $\mathrm{O}_{2}$ shown below: [42]
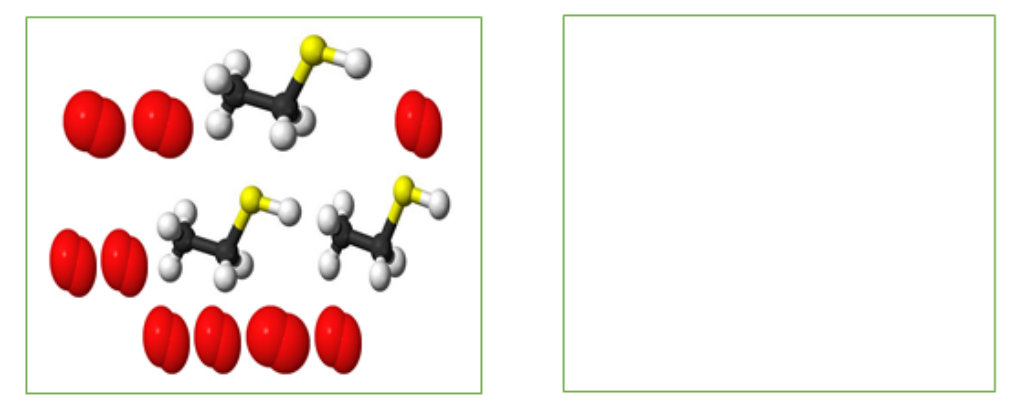

*The drawing is not to scale.

4) How many aluminium atoms are required in order to have the same mass as one quinine molecule, $\mathrm{C}_{20} \mathrm{H}_{24} \mathrm{~N}_{2} \mathrm{O}_{2}($ an antimalarial drug)?

[Molar mass of $\mathrm{Al}=26.982 \mathrm{~g} \mathrm{~mol}^{-1}$; Molar mass of $\mathrm{C}_{20} \mathrm{H}_{24} \mathrm{~N}_{2} \mathrm{O}_{2}=324.42 \mathrm{~g} \mathrm{~mol}^{-1}$ ]

5) $0.56 \mathrm{~g}$ of gas $P$ occupies $448 \mathrm{~cm}^{3}$ at standard temperature and pressure (STP). What is the relative molecular mass of $P$ ? [Molar volume of gas at STP $=22.4 \mathrm{dm}^{3} \mathrm{~mol}^{-1}$ ]

6) What is the percentage composition by mass of water in hydrated copper (II) sulfate, $\mathrm{CuSO}_{4} \cdot 5 \mathrm{H}_{2} \mathrm{O}_{\text {? }}$ [Molar mass of $\mathrm{CuSO}_{4} .5 \mathrm{H}_{2} \mathrm{O}=249.72 \mathrm{~g} \mathrm{~mol}^{-1}$; Molar mass of $\mathrm{H}_{2} \mathrm{O}=18.015 \mathrm{~g} \mathrm{~mol}^{-1}$ ]

7) The following equation represents the reaction between magnesium and oxygen:

$2 \mathrm{Mg}+\mathrm{O}_{2} \rightarrow 2 \mathrm{MgO}$

What is the maximum mass of magnesium oxide formed when $60 \mathrm{~g}$ of magnesium is completely burnt in the presence of oxygen?

[Molar mass of $\mathrm{Mg}=24.305 \mathrm{~g} \mathrm{~mol}^{-1}$; Molar mass of $\mathrm{O}=15.999 \mathrm{~g} \mathrm{~mol}^{-1}$ ] 
8) A mixture of $\mathrm{H}_{2}(\mathrm{~g})$ and $\mathrm{N}_{2}(\mathrm{~g})$ reacted in a closed vessel to form $\mathrm{NH}_{3}(\mathrm{~g})$. The reaction ceased before either reactant

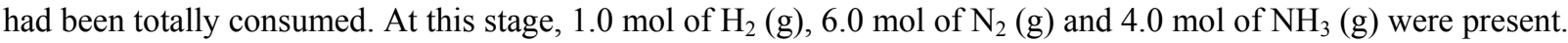
How many mol of $\mathrm{H}_{2}(\mathrm{~g})$ and $\mathrm{N}_{2}(\mathrm{~g})$ were present originally?

[Molar mass of $\mathrm{H}=1.008 \mathrm{~g} \mathrm{~mol}^{-1}$; Molar mass of $\mathrm{N}=14.007 \mathrm{~g} \mathrm{~mol}^{-1}$ ]

9) In the absence of a catalyst, ammonia burns in an excess of oxygen to produce steam and nitrogen. What is the remaining volume of oxygen when $80 \mathrm{~cm}^{3}$ of ammonia is burnt in $200 \mathrm{~cm}^{3}$ of oxygen (all volumes being measured at the same temperature and pressure)?

[Molar mass of $\mathrm{H}=1.0079 \mathrm{~g} \mathrm{~mol}^{-1}$; Molar mass of $\mathrm{N}=14.007 \mathrm{~g} \mathrm{~mol}^{-1}$; Molar mass of $\mathrm{O}=15.999 \mathrm{~g} \mathrm{~mol}^{-1}$ ] (Adapted from Cambridge A Level, 1986)

10) Bone contains a complex mixture of calcium salts, proteins and other materials. When a bone is strongly heated in a current of air, the only residue is calcium oxide. From a sample of $45.0 \mathrm{~g}$ of bone, $10.0 \mathrm{~g}$ of calcium oxide were obtained. What is the percentage by mass of calcium in the bone?

[Molar mass of $\mathrm{O}=15.999 \mathrm{~g} \mathrm{~mol}^{-1}$; Molar mass of $\mathrm{Ca}=40.078 \mathrm{~g} \mathrm{~mol}^{-1}$ ]

11) Iron burns in chlorine gas to form iron chloride. In a laboratory, an experiment showed that $5.60 \mathrm{~g}$ of iron combined with $10.65 \mathrm{~g}$ of chlorine. Deduced the balanced equation for the reaction.

[Molar mass of $\mathrm{Cl}=35.45 \mathrm{~g} \mathrm{~mol}^{-1}$; Molar mass of $\mathrm{Fe}=55.845 \mathrm{~g} \mathrm{~mol}^{-1}$ ]

12) An element $\mathrm{Y}$ forms an iodide $\left(\mathrm{YI}_{3}\right)$ and a chloride $\left(\mathrm{YCl}_{3}\right)$. The iodide is quantitatively converted to the chloride when it is heated with chlorine:

$2 \mathrm{YI}_{3}+3 \mathrm{Cl}_{2} \rightarrow 2 \mathrm{YCl}_{3}+3 \mathrm{I}_{2}$

If $0.5000 \mathrm{~g}$ of $\mathrm{YI}_{3}$ is used, $0.23660 \mathrm{~g}$ of $\mathrm{YCl}_{3}$ is obtained. Calculate the molar mass of the element $\mathrm{Y}$.

$\left[\right.$ Molar mass of $\mathrm{Cl}=35.45 \mathrm{~g} \mathrm{~mol}^{-1}$; Molar mass of $\mathrm{I}=126.904 \mathrm{~g} \mathrm{~mol}^{-1}$ ]

13) Which will contain the greater number of moles of potassium ion: $30.0 \mathrm{~cm}^{3}$ of $0.200 \mathrm{~mol} \mathrm{dm}^{-3} \mathrm{~K}_{2} \mathrm{CrO}_{4}$ or $25.0 \mathrm{~cm}^{3}$ of $0.1000 \mathrm{~mol} \mathrm{dm}^{-3} \mathrm{~K}_{3} \mathrm{PO}_{4}$ ?

[Molar mass of $\mathrm{O}=15.999 \mathrm{~g} \mathrm{~mol}^{-1}$; Molar mass of $\mathrm{P}=30.974 \mathrm{~g} \mathrm{~mol}^{-1}$; Molar mass of $\mathrm{K}=39.098 \mathrm{~g} \mathrm{~mol}^{-1}$; Molar mass of $\left.\mathrm{Cr}=51.996 \mathrm{~g} \mathrm{~mol}^{-1}\right]$

14) Nervous disorder resulting from mercury poisoning occurs because mercury forms a 1:1 complex with lipopyl groups which are vital for glucose metabolism. If the average concentration of lipopyl groups in the body fluid is 1.0 x $10^{-8} \mathrm{~mol} \mathrm{~kg}^{-1}$, calculate the mass of mercury (in gram) which could complex all the lipopyl groups in a human containing $6.0 \mathrm{~kg}$ of body fluid.

[Molar mass of $\mathrm{Hg}=200.592 \mathrm{~g} \mathrm{~mol}^{-1}$ ] 
15) The following equation represents the reaction between $50 \mathrm{~cm}^{3}$ of $0.5 \mathrm{~mol} \mathrm{dm}$-3 nitric acid and excess magnesium carbonate:

$\mathrm{MgCO}_{3}+2 \mathrm{HNO}_{3} \rightarrow \mathrm{Mg}\left(\mathrm{NO}_{3}\right)_{2}+\mathrm{H}_{2} \mathrm{O}+\mathrm{CO}_{2}$

What is the volume of carbon dioxide released from the reaction at room condition? [Molar volume of gas at room condition $\left.=24 \mathrm{dm}^{3} \mathrm{~mol}^{-1}\right]$

[Molar mass of $\mathrm{H}=1.008 \mathrm{~g} \mathrm{~mol}^{-1}$; mass of $\mathrm{C}=12.011 \mathrm{~g} \mathrm{~mol}^{-1}$; Molar mass of $\mathrm{O}=15.999 \mathrm{~g} \mathrm{~mol}^{-1}$; Molar mass of $\mathrm{N}=$ $14.007 \mathrm{~g} \mathrm{~mol}^{-1}$; Molar mass of $\mathrm{Mg}=24.305 \mathrm{~g} \mathrm{~mol}^{-1}$ ]

16) Two reactions are given below:

$2 \mathrm{Mg}+\mathrm{CO}_{2} \rightarrow 2 \mathrm{MgO}+\mathrm{C}$

$\mathrm{MgO}+2 \mathrm{HCl} \rightarrow \mathrm{MgCl}_{2}+\mathrm{H}_{2} \mathrm{O}$

$m \mathrm{~g}$ of magnesium reacts completely with carbon dioxide to form magnesium oxide. If $34.50 \mathrm{~cm}^{3}$ of $0.50 \mathrm{~mol} \mathrm{dm}^{-3}$ hydrochloric acid is required to dissolve completely all the magnesium oxide formed, what is the value of $m$ ?

[Molar mass of $\mathrm{H}=1.008 \mathrm{~g} \mathrm{~mol}^{-1}$; Molar mass of $\mathrm{C}=12.011 \mathrm{~g} \mathrm{~mol}^{-1}$; Molar mass of $\mathrm{O}=15.999 \mathrm{~g} \mathrm{~mol}^{-1}$; Molar mass of $\mathrm{Mg}=24.305 \mathrm{~g} \mathrm{~mol}^{-1}$; Molar mass of $\left.\mathrm{Cl}=35.45 \mathrm{~g} \mathrm{~mol}^{-1}\right]$

17) What are the concentrations of IONS formed in a $0.20 \mathrm{~mol} \mathrm{dm}^{-3}$ solution of $\mathrm{Al}_{2}\left(\mathrm{SO}_{4}\right)_{3}$ ?

$\left[\right.$ Molar mass of $\mathrm{O}=15.999 \mathrm{~g} \mathrm{~mol}^{-1}$; Molar mass of Al $=26.982 \mathrm{~g} \mathrm{~mol}^{-1}$; Molar mass of S $=32.06 \mathrm{~g} \mathrm{~mol}^{-1}$ ]

18) The maximum allowed concentration of chloride ion, $\mathrm{Cl}^{-}$, in a municipal drinking water supply is $2.50 \times 10^{2} \mathrm{ppm}$. When the supply of water exceeds this limit, it often has a distinctive salty taste. What is the allowed concentration of $\mathrm{Cl}^{-}$in $\mathrm{mol} / \mathrm{L}$ ?

[Molar mass of $\mathrm{Cl}=35.45 \mathrm{~g} \mathrm{~mol}^{-1}$ ]

19) The equation represents a neutralization reaction:

$2 \mathrm{HNO}_{3}+\mathrm{Ba}(\mathrm{OH})_{2} \rightarrow \mathrm{Ba}\left(\mathrm{NO}_{3}\right)_{2}+2 \mathrm{H}_{2} \mathrm{O}$

$10.0 \mathrm{~cm}^{3}$ of $0.1 \mathrm{~mol} \mathrm{dm}^{-3}$ barium hydroxide solution is titrated with $0.10 \mathrm{~mol} \mathrm{dm}^{-3}$ nitric acid. If the initial reading of the burette is $10.00 \mathrm{~cm}^{3}$, what is the final reading of the burette?

[Molar mass of $\mathrm{H}=1.008 \mathrm{~g} \mathrm{~mol}^{-1}$; Molar mass of $\mathrm{O}=15.999 \mathrm{~g} \mathrm{~mol}^{-1}$; Molar mass of $\mathrm{N}=14.007 \mathrm{~g} \mathrm{~mol}^{-1}$; Molar mass of $\mathrm{Ba}=137.327 \mathrm{~g}$ mol-1]

20) The concentrated hydrochloric acid, $\mathrm{HCl}$ is peddled commercially with $37.0 \%$ by weight and its density is $1.18 \mathrm{~g}$ $\mathrm{cm}^{-3}$. How many $\mathrm{cm}^{3}$ of the concentrated $\mathrm{HCl}$ is required to prepare $500.0 \mathrm{~cm}^{3}$ of $0.050 \mathrm{~mol} \mathrm{dm}^{-3} \mathrm{HCl}$ ?

[Molar mass of $\mathrm{H}=1.008 \mathrm{~g} \mathrm{~mol}^{-1}$; Molar mass of $\mathrm{Cl}=35.45 \mathrm{~g} \mathrm{~mol}^{-1}$ ]

21) $100.0 \mathrm{~cm}^{3}$ of concentrated $\mathrm{H}_{2} \mathrm{SO}_{4}$ was diluted to $1000.0 \mathrm{~cm}^{3}$ with distilled water. The diluted acid was titrated against $25.0 \mathrm{~cm}^{3}$ of $0.650 \mathrm{~mol} \mathrm{dm}^{-3}$ sodium hydroxide, $\mathrm{NaOH} .27 .45 \mathrm{~cm}^{3}$ of $\mathrm{H}_{2} \mathrm{SO}_{4}$ is required for neutralization. What was the initial concentration of the $\mathrm{H}_{2} \mathrm{SO}_{4}$ ?

[Molar mass of $\mathrm{H}=1.008 \mathrm{~g} \mathrm{~mol}^{-1}$; Molar mass of $\mathrm{O}=15.999 \mathrm{~g} \mathrm{~mol}^{-1}$; Molar mass of $\mathrm{S}=32.06 \mathrm{~g} \mathrm{~mol}^{-1}$ ] 
22) Solution A is prepared by dissolving $90.0 \mathrm{~g}$ of $\mathrm{Na}_{3} \mathrm{PO}_{4}$ in water to make $1.0 \mathrm{dm}^{3}$ of solution. Solution $\mathrm{B}$ is $2.0 \mathrm{~L}$ of $0.710 \mathrm{~mol} \mathrm{dm}^{-3} \mathrm{Na}_{2} \mathrm{SO}_{4}$ (aq).

a) What is the molar concentration of $\mathrm{Na}_{3} \mathrm{PO}_{4}$ in solution $\mathrm{A}$ ?

b) What volume of solution A contains $2.50 \mathrm{~g}$ of $\mathrm{Na}_{3} \mathrm{PO}_{4}$ ?

c) A $55.0 \mathrm{~cm}^{3}$ sample of solution B is mixed with $70.00 \mathrm{~cm}^{3}$ sample of solution A. Calculate the concentration of $\mathrm{Na}^{+}$ions in the final solution.

[Molar mass of $\mathrm{O}=15.999 \mathrm{~g} \mathrm{~mol}^{-1}$; Molar mass of $\mathrm{Na}=22.990 \mathrm{~g} \mathrm{~mol}^{-1}$; Molar mass of $\mathrm{P}=30.974 \mathrm{~g} \mathrm{~mol}^{-1}$; Molar mass of $\left.\mathrm{S}=32.06 \mathrm{~g} \mathrm{~mol}^{-1}\right][42]$

23) A chemist needs a solution that contains aluminium ions, sodium ions and sulfate ions. In the laboratory she finds a large volume of $0.455 \mathrm{~mol} \mathrm{dm}^{-3}$ sodium sulfate solution and a bottle of solid $\mathrm{Al}_{2}\left(\mathrm{SO}_{4}\right)_{3} \cdot 18 \mathrm{H}_{2} \mathrm{O}$. The chemist puts 200 $\mathrm{cm}^{3}$ of the sodium sulfate solution and $6.13 \mathrm{~g}$ of aluminium sulfate hydrate in a $500 \mathrm{~cm}^{3}$ volumetric flask. The flask is made up to the mark with water. Determine the molarity of aluminium ions, sodium ions and sulfate ions in the solution.

[Molar mass of Na $=22.990 \mathrm{~g} \mathrm{~mol}^{-1}$; Molar mass of $\mathrm{Al}=26.982 \mathrm{~g} \mathrm{~mol}^{-1}$; Molar mass of $\mathrm{S}=32.06 \mathrm{~g} \mathrm{~mol}^{-1}$; Molar mass of $\left.\mathrm{Al}_{2}\left(\mathrm{SO}_{4}\right)_{3} \cdot 18 \mathrm{H}_{2} \mathrm{O}=666.4 \mathrm{~g} \mathrm{~mol}^{-1}\right]$ [42]

24) Pure acetic acid, $\mathrm{CH}_{3} \mathrm{COOH}$, has a concentration of $17.4 \mathrm{~mol} \mathrm{dm}^{-3}$. A laboratory worker measured out $150.0 \mathrm{~cm}^{3}$ of pure acetic acid and added enough water to make $500.0 \mathrm{~cm}^{3}$ of solution. A $65.0 \mathrm{~cm}^{3}$ portion of the acetic solution was then mixed with enough water to make $1.50 \mathrm{dm}^{3}$ of dilute solution. What was the final molarity of acetic acid in the dilute solution?

[Molar mass of $\mathrm{H}=1.008 \mathrm{~g} \mathrm{~mol}^{-1}$; Molar mass of $\mathrm{C}=12.011 \mathrm{~g} \mathrm{~mol}^{-1}$; Molar mass of $\left.\mathrm{O}=15.999 \mathrm{~g} \mathrm{~mol}^{-1}\right]$ [42]

25) Glass beaker $X$ contains twice the volume of solution as that in beaker $Z$. If four molecules of glucose are dissolved in $\mathrm{Z}$ as shown below: [26]

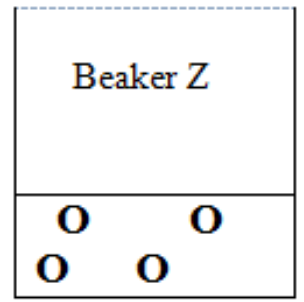

(i) Which one of the following alternatives represent beaker $\mathrm{X}$ if the glucose concentrations are the same in both beakers?

(a)

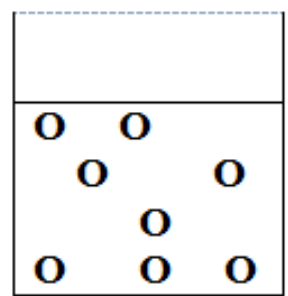

(b)

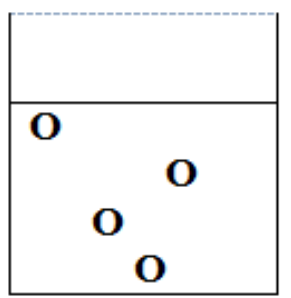

(c)

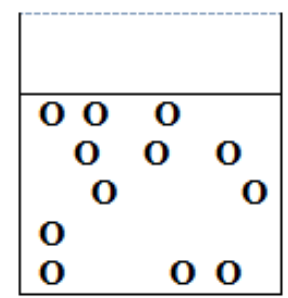

Explain your answer. 
(ii) Which one of the following alternatives represent beaker $\mathrm{X}$ if the sugar concentration in $\mathrm{X}$ is half the concentration in beaker Z?

(a)

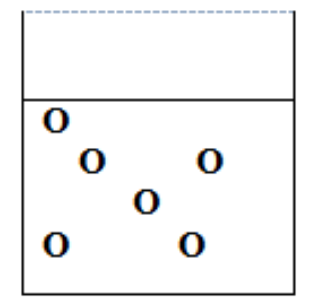

(b)

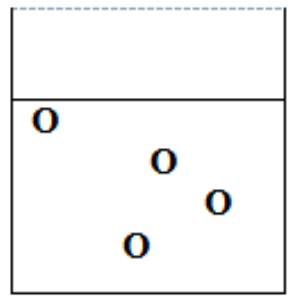

(c)

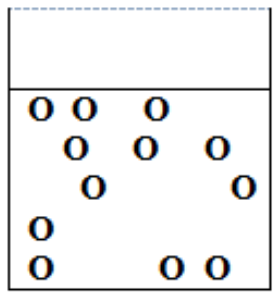

Explain your answer.

THE END

\section{REFERENCES}

[1] N. Reid. The presentation of chemistry logically driven or applications-led? Chemistry Education Research and Practice, Vol.1, No.3, 381-392, 2000.

[2] N. Becker, C. Stanford, M. Towns, R. Cole. Translating across macroscopic, submicroscopic, and symbolic levels: the role of instructor facilitation in an inquiry-oriented physical chemistry class, Chemistry Education Research and Practice, Vol.16, No.4, 2015.

[3] K. L. Evans, D. Yaron, G. Leinhardt. Learning stoichiometry: A comparison of text and multimedia formats, Chemistry Education Research and Practice., Vol.9, No.3, 2008.

[4] Y. J. Dori, M. Hameiri. Multidimensional analysis system for quantitative chemistry problems: Symbol, macro, micro, and process aspects, Journal of Research in Science Teaching, Vol.40, No.3, 2003.

[5] A. H. Johnstone. The development of chemistry teaching: A changing response to changing demand, Journal of Chemical Education, Vol.70, No.9, 701, 1993.

[6] A. H. Johnstone. Why is science difficult to learn? Things are seldom what they seem, J Comp Assist Learn Journal of Computer Assisted Learning, Vol.7, No.2, 75-83, 1991.

[7] R. Duit, D. F. Treagust. Conceptual change: A powerful framework for improving science teaching and learning, International Journal of Science Education, Vol.25, No.6, 671-688, 2003.

[8] K. Y. Hoe, R. Subramaniam. On the prevalence of alternative conceptions on acid-base chemistry among secondary students: Insights from cognitive and confidence measures, Chemistry Education Research and Practice, Vol.17, No.2, 263-282, 2016.

[9] S. Lu, H. Bi. Development of a measurement instrument to assess students' electrolyte conceptual understanding, Chemistry Education Research and Practice, Vol.17, No.4,
1030-1040, 2016.

[10] A. L. Chandrasegaran, D. F. Treagust, M. Mocerino. The development of a two-tier multiple-choice diagnostic instrument for evaluating secondary school students' ability to describe and explain chemical reactions using multiple levels of representation, Chemistry Education Research and Practice, Vol.8 No.3, 2007.

[11] L. C. Mcdermott. Millikan Lecture 1990: What we teach and what is learned-closing the gap, American Journal of Physics, Vol.59, No.4, 301, 1991.

[12] B. P. Gilchrist. The mole concept: Teaching and learning, Australian Science Teachers Journal, Vol.28, No.2, 87-97. 1982.

[13] K. W. Voska, H. W. Heikkinen. Identification and analysis of student conceptions used to solve chemical equilibrium problems, Journal of Research in Science Teaching, Vol. 37, No.2, 160-176, 2000.

[14] C. A. Randles, T. L. Overton. Expert vs. novice: approaches used by chemists when solving open-ended problems. Chemistry Education Research and Practice, Vol.16, No.4, 811-823, 2015.

[15] C. Furio, R. Azcona, J. Guisasola. The learning and teaching of the concepts 'amount of substance' and 'mole': A review of the literature, Chemistry Education Research and Practice, Vol. 3, No.3, 277-292, 2002.

[16] P. Chonkaew, B. Sukhummek, C. Faikhamta. Development of analytical thinking ability and attitudes towards science learning of grade-11 students through science technology engineering and mathematics (STEM education) in the study of stoichiometry, Chemistry Education Research and Practice, Vol.17, No.4, 842-861, 2016.

[17] S. Fang, C. Hart, D. Clarke. Identifying the critical components for a conceptual understanding of the mole in secondary science classrooms, Journal of Research in Science Teaching, Vol.53, No.2, 181-214, 2015.

[18] G. Gorin. Mole, mole per liter, and molar: A primer on SI and related units for chemistry students, Journal of Chemical Education, Vol.80, No.1, 103, 2003. 
[19] B. Pekdağ, N. Azizoğlu. Semantic mistakes and didactic difficulties in teaching the "amount of substance" concept: a useful model, Chemistry Education Research and Practice, Vol.14, No.1, 117-129, 2013.

[20] H. Schmidt, C. Jignéus. Students' strategies in solving algorithmic stoichiometry problems, Chemistry Education Research and Practice, Vol.4, No.3, 305-317, 2003.

[21] A. L. Chandrasegaran, D. F. Treagust, B. G. Waldrip. Students' dilemmas in reaction stoichiometry problem solving: Deducing the limiting reagent in chemical reactions, Chemistry Education Research and Practice, Vol.10, No.1, 14-23, 2009.

[22] L. Gauchon, M. Méheut. Learning about stoichiometry: From students' preconceptions to the concept of limiting reactant, Chemistry Education Research and Practice, Vol. 8 , No.4, 362-375, 2007.

[23] S. BouJaoude, H. Barakat. Secondary school students' difficulties with stoichiometry, School Science Review, Vol.296, No.81, 91-98, 2000.

[24] J. Lythcott. Problem solving and requisite knowledge of chemistry, Journal of Chemical Education, Vol. 67, No. 3, 248,1990 .

[25] G. Nicoll. A report of undergraduates' bonding misconceptions, International Journal of Science Education, Vol.23, No.7, 707-730, 2001.

[26] K. D. Berg. A study of first-year chemistry students' understanding of solution concentration at the tertiary level, Chemistry Education Research and Practice, Vol.13, No.1, 8-16, 2012.

[27] Ministry of Education Malaysia. Integrated curriculum for secondary schools: Curriculum specifications, chemistry form 4, Curriculum Development Centre, Ministry of Education Malaysia, 2005.

[28] M. Calik, A. Ayas. A cross-age study on the understanding of chemical solutions and their components, International Education Journal, Vol.6, No.1, 30-41, 2005.

[29] I. Devetak, J. Vogrinc, S. A. Glažar. Assessing 16-year-old students' understanding of aqueous solution at submicroscopic level, Research in Science Education, Vol.39, No.2, 157-179, 2008.

[30] A. Vincent. Volumetric concepts-student difficulties, Education in Chemistry, Vol.4, 114-115, 1981.

[31] F. Ö. Karataş. Pre-service chemistry teachers' competencies in the laboratory: a cross-grade study in solution preparation,
Chemistry Education Research and Practice, Vol.17, No.1, 100-110, 2016.

[32] V. D. Kostić, V. P. Jovanović, T. M. Sekulić, D. B. Takači. Visualization of problem solving related to the quantitative composition of solutions in the dynamic GeoGebra environment, Chemistry Education Research and Practice, Vol.17, No.1, 120-138, 2016.

[33] C. R. Reynolds, R. B. Livingston, V. L. Willson Measurement and Assessment in Education. Boston, Pearson/Allyn \& Bacon, 2006.

[34] I. S. Caleon, R. Subramaniam. Do students know what they know and what they don't know? Using a four-tier diagnostic test to assess the nature of students' alternative conceptions, Research in Science Education, Vol.40 No.3, 2009.

[35] D. F. Treagust. Development and use of diagnostic tests to evaluate students' misconceptions in science, International Journal of Science Education, Vol.10, No.2, 159-169, 1988.

[36] C. Tsai, C. Chou, C. Diagnosing students' alternative conceptions in science, Journal of Computer Assisted Learning, Vol.18, No.2, 157-165. 2002.

[37] D. K. Gurel, A. Eryilmaz, L. C. McDermott. A review and comparison of diagnostic instruments to identify students' misconceptions in science, EURASIA Journal of Mathematics, Science and Technology Education, Vol.11, No.5, 989-1008, 2015 .

[38] Y. K. Yan, R. Subramaniam. (2018). Using a multi-tier diagnostic test to explore the nature of students' alternative conceptions on reaction kinetics, Chemistry Education Research and Practice, Vol.19, No.1, 2018.

[39] R. Galloway. Diagnostic testing. In M. Grove, T. Overton (Eds.). Getting Started in Pedagogic Research within the STEM Disciplines (1st ed., pp. 29-31), Birmingham, University of Birmingham, 2013.

[40] M. Rollnick, P. P. Mahooana. A quick and effective way of diagnosing student difficulties: Two tier from simple multiple-choice questions, South African Journal of Chemistry, Vol.52, No.4, 161-164, 1999.

[41] D. Kaltakçi. Development and application of a four-tier test to assess pre-service physics teachers' misconceptions about geometrical optics (Unpublished Ph.D thesis, Middle East Technical University), 2012.

[42] A. Blackman, S. Bottle, S. Schmid, M. Mocerino, U. Wille. Chemistry, Hoboken, NJ: Wiley, 2016. 